\title{
The linked units of $5 S$ rDNA and U1 snDNA of razor shells (Mollusca: Bivalvia: Pharidae)
}

\author{
J Vierna ${ }^{1}$, KT Jensen ${ }^{2}$, A Martínez-Lage ${ }^{1}$ and AM González-Tizón ${ }^{1}$ \\ ${ }^{1}$ Department of Molecular and Cell Biology, Evolutionary Biology Group (GIBE), Universidade da Coruña, La Coruña, Spain \\ and ${ }^{2}$ Marine Ecology, Department of Biological Sciences, Aarhus University, Ole Worms Allé 1, Aarhus C, Denmark
}

\begin{abstract}
The linkage between 5S ribosomal DNA and other multigene families has been detected in many eukaryote lineages, but whether it provides any selective advantage remains unclear. In this work, we report the occurrence of linked units of $5 S$ ribosomal DNA (5S rDNA) and U1 small nuclear DNA (U1 snDNA) in 10 razor shell species (Mollusca: Bivalvia: Pharidae) from four different genera. We obtained several clones containing partial or complete repeats of both multigene families in which both types of genes displayed the same orientation. We provide a comprehensive collection of razor shell 5S rDNA clones, both with linked and nonlinked organisation, and the first bivalve U1 snDNA sequences. We predicted the secondary structures and characterised the upstream and downstream conserved elements, including a region at -25 nucleotides from both $5 S$ rDNA and U1 snDNA
\end{abstract}

transcription start sites. The analysis of 5S rDNA showed that some nontranscribed spacers (NTSs) are more closely related to NTSs from other species (and genera) than to NTSs from the species they were retrieved from, suggesting birth-and-death evolution and ancestral polymorphism. Nucleotide conservation within the functional regions suggests the involvement of purifying selection, unequal crossing-overs and gene conversions. Taking into account this and other studies, we discuss the possible mechanisms by which both multigene families could have become linked in the Pharidae lineage. The reason why $5 S$ rDNA is often found linked to other multigene families seems to be the result of stochastic processes within genomes in which its high copy number is determinant.

Heredity (2011) 107, 127-142; doi:10.1038/hdy.2010.174; published online 2 March 2011

Keywords: birth-and-death evolution; regulatory regions; 5 S ribosomal RNA; U1 small nuclear RNA; linkage; Ensis

\section{Introduction}

The 5S ribosomal RNA molecule (5S rRNA) is a component of the large subunit of ribosomes, encoded by the $5 S$ ribosomal DNA ( $5 S$ rDNA) and transcribed by RNA polymerase III. The eukaryote $5 S$ rDNA is a multigene family, typically composed of hundreds of repeats of an approximately 120 nucleotides (nts) RNA coding region (hereafter, 5S) and an intergenic spacer (IGS) usually referred to as nontranscribed spacer (NTS). The first nts downstream the 5S are transcribed as part of the primary RNA and deleted during RNA maturation (Sharp et al., 1984; Sharp and Garcia, 1988), but they are considered as part of the NTS.

The 5S rDNA is characterised by a flexible organisation, as it has been found in clusters composed of similar or divergent tandemly arranged repeats (differences mainly occur within the NTS; for example, ShippenLentz and Vezza, 1988), and in clusters of 5S rDNA repeats tandemly linked to other multigene families (for example, Cross and Rebordinos, 2005; Freire et al., 2010; Cabral-de-Mello et al., 2010). A dispersed organisation of $5 S$ rDNA has also been reported (Morzycka-Wroblewska

Correspondence: J Vierna or AM González-Tizón, Department of Molecular and Cell Biology, Evolutionary Biology Group (GIBE), Universidade da Coruña, A Fraga, 10, La Coruña E-15008, Spain.

E-mails: jvierna@udc.es; joaquinvierna@gmail.com or hakuna@udc.es

Received 12 July 2010; revised 18 October 2010; accepted

8 November 2010; published online 2 March 2011 et al., 1985 and references therein), and some species were found to have more than one type of organisation within the genome (Little and Braaten, 1989).

The 5S rDNA multigene family was thought to be characterised by low levels of intragenomic divergence in virtually all species because of the concerted evolution of ribosomal multigene families (see Eickbush and Eickbush, 2007 for a review). Nevertheless, the ocurrence of divergent variants of $5 S$ rDNA within a genome has been described in animals, plants and fungi (for example, Fernandez et al., 2005; Rooney and Ward, 2005; Caradonna et al., 2007), and in some cases, differences in the RNA coding regions were found to correspond to tissue-specific variants (Peterson et al., 1980). Therefore, recent studies have pointed out to a more complex evolutionary scenario in which birth-and-death processes generate new $5 S$ rDNA variants that may be homogenised by unequal crossing-overs and gene conversions. For instance, in Ensis razor shells (Schumacher, 1817), the long-term evolution of 5S rDNA was found to be driven by birth-and-death processes and selection, and it was suggested that homogenising mechanisms were also taking part within each variant in each species (Vierna et al., 2009). Later on, it was proposed that the levels of intragenomic divergence-much higher within the $5 S$ rDNA than within the major ribosomal geneswere due to the more flexible organisation of $5 \mathrm{~S}$ rDNA, meaning that homogenisation processes were more efficient within the array(s) of major ribosomal genes, as they may occur in a smaller number. The long-term 
evolution of both rDNA regions was then proposed to be driven by a mixed process of concerted evolution, birth-and-death evolution and purifying selection, as described by Nei and Rooney (2005) (Vierna et al., 2010).

Most eukaryotic genes are transcribed into precursor messenger RNAs that must undergo splicing, an essential step of gene expression. During precursor messenger RNA splicing, introns are removed from the precursor messenger RNA and exons are ligated together to form mRNA (Will and Lührmann, 2005). Splicing is performed by the spliceosomes, ribonucleoprotein complexes consisting of small nuclear RNAs and several proteins. The U1 small nuclear RNA molecule is a component of the major spliceosome, essential for the interaction with the $5^{\prime}$ splice site of introns (Zhuang and Weiner, 1986). This molecule is encoded by the U1 small nuclear DNA (U1 snDNA), which consists of an RNA coding region (hereafter, U1) and an IGS (when it is organised in tandem repeats). U1 snDNA, transcribed by RNA polymerase II, is a multigene family with a variable number of repeats in each genome (around tens of repeats in the metazoan species studied by Marz et al., 2008). Although not much information is available about the organisation of U1 snDNA, it was found to be linked to other multigene families, such as $5 \mathrm{~S}$ rDNA (Pelliccia et al., 2001), other spliceosomal snDNA families (Marz et al., 2008) and organised in the same array together with 5S rDNA repeats and other spliceosomal snDNA (Manchado et al., 2006). In general, however, clustered copies of distinct or the same small nuclear RNA coding genes are not common in metazoan genomes (Marz et al., 2008).

The evolution of spliceosomal snDNA has been recently studied in two different surveys, covering insect species (Mount et al., 2007) and several other metazoan groups (Marz et al., 2008), and appears not to be a simple issue. In insects, it is governed by several concurrent forces, namely purifying selection, unequal crossingovers, gene conversions and birth-and-death processes (Mount et al., 2007). Distinguishable U1 snDNA paralogs differentially expressed throughout development have been described in some species (for example, Lo and Mount, 1990), but the snDNA paralog groups seem not to be stable over a long evolutionary time, although they appear independently in several clades (Marz et al., 2008).

The linkage between $5 S$ rDNA and U1 snDNA has only been reported in one crustacean (Pelliccia et al., 2001) and in one fish (Manchado et al., 2006). In this survey, we report linked units of $5 S$ rDNA and U1 snDNA in 10 razor shell species (Mollusca: Bivalvia: Pharidae) from four different genera. We obtained new data about the genomic organisation of both multigene families in these animals, and studied the genesis and evolution of the $5 \mathrm{~S}$ rDNA-U1 snDNA linked units. Using the Ensis sequences available from DDBJ/EMBL/GenBank and the new sequences obtained, we provide a comprehensive collection of razor shell $5 S$ rDNA variants, including their secondary structures and the characterisation of putative pseudogenes. We also report the first Bivalvia U1 snDNA sequences, including their predicted secondary structures. Finally, several putative regulatory regions of both multigene families were studied in detail.

\section{Materials and methods}

\section{Animals}

We selected 11 species belonging to family Pharidae (Adams and Adams, 1858; Mollusca: Bivalvia, Table 1). Though a greater sampling effort was made on genus Ensis, we tried to represent the whole family by selecting species from its different subtaxons. Thus, from subfamily Cultellinae (Davies, 1935), we studied eight Ensis species and one Ensiculus (Adams, 1860). The species Siliqua patula (Dixon, 1789) was also included in the analysis, as genus Siliqua (Mühlfeld, 1811) may represent a separate subfamily from the Cultellinae (see Cosel, 1993). From the other subfamily, Pharinae (Adams and Adams, 1858), we took into consideration the species Pharus legumen (Linné, 1758). Two homonymous species, Ensis minor (Chenu, 1843) and E. minor (Dall, 1899) were studied in this survey, and hereafter they will be referred to as E. minor (Chenu) and E. minor (Dall). All taxon names follow Cosel (1993) and Cosel (2009), when applicable. Razor shells were provided by several colleagues and preserved in $100 \%$ ethanol until species identification, except the Ensiculus cultellus (Linné, 1758) sample that consisted of an ethanol-preserved piece of muscle tissue, and Ensis goreensis (Clessin, 1888) from which only dried tissue was available.

\section{DNA extraction, PCR, cloning and sequencing}

DNA extractions were done from muscle tissue using the NucleoSpin Tissue kit (Macherey-Nagel, North RhineWestphalia, Germany). Using the primers 5S-Univ-F and 5S-Univ-R (Vierna et al., 2009), we serendipitously amplified complete U1 snDNA sequences flanked by two partial 5S rDNA repeats in the species Ensis magnus (Schumacher, 1817) and P. legumen. From these sequences, different primer pairs annealing at the $5 S$ and U1 regions of razor shells were designed using GeneFisher (Giegerich et al., 1996) (Table 2). PCR reactions were conducted in a final volume of $20 \mu \mathrm{l}$ using the $2 \times$ Taq Master Mix RED (VWR/Ampliqon, Skovlunde, Denmark), applying the following conditions: an initial denaturation step at $94^{\circ} \mathrm{C}$ for $3 \mathrm{~min}$ followed by 40 cycles of denaturation at $94{ }^{\circ} \mathrm{C}$ for $20 \mathrm{~s}$, annealing at the temperatures indicated in Table 2 for $20 \mathrm{~s}$, extension at $72{ }^{\circ} \mathrm{C}$ for $1 \mathrm{~min}$, and a final extension at $72{ }^{\circ} \mathrm{C}$ for $5 \mathrm{~min}$. Amplification products were run on $1 \%$ agarose gels, stained with a $0.5 \mu \mathrm{g} / \mathrm{ml}$ solution of ethidium bromide, and imaged under UV light. They were cloned using the TOPO TA cloning kit (Invitrogen, Carlsbad, CA, USA). A subset of transformant colonies from each cloning reaction was analysed by PCR in order to check the insert size. From each PCR, we selected one clone per species when only one band was retrieved (that is, in all cases except in one of the PCRs of Ensis macha (Molina, 1782) and E. cultellus individuals, in which case we obtained two slightly different bands, so two clones were sequenced). Sequencing was performed at Macrogen (Seoul, South Korea) using both T3 and T7 primers (forward and reverse) included in the cloning kit.

\section{Bioinformatic analyses}

Electropherograms were inspected in BioEdit 7.0.9.0 (Hall, 1999). The Blast 2 sequences tool (available at www.ncbi.nlm.nih.gov/blast/bl2seq/wblast2.cgi) was 
Table 2 Primer pairs used in this survey

\begin{tabular}{llccc}
\hline Sequence/reference & $T$ & a.r. & a.p. \\
\hline 5S-Univ-F & Vierna et al. (2009) & $50^{\circ} \mathrm{C}$ & $5 \mathrm{~S}$ & $13-32$ \\
5S-Univ-R & Vierna et al. (2009) & $50^{\circ} \mathrm{C}$ & $5 \mathrm{~S}$ & $36-55$ \\
& & & & \\
5S-U1-F & $5^{\prime}$ GTCTACGGCCATATCACGTT & $61^{\circ} \mathrm{C}$ & $5 \mathrm{~S}$ & $1-20$ \\
5S-U1-R & $5^{\prime}$ GTTAGCGCGAACGCAGVC & $61^{\circ} \mathrm{C}$ & U1 & $142-159$ \\
& & & & \\
U1-5S-F & $5^{\prime}$ VCTGCGTTCGCGCTAVCC & $65^{\circ} \mathrm{C}$ & U1 & $143-160$ \\
U1-5S-R & $5^{\prime}$ GGTATTCCCAGGCGGTCAC & $65^{\circ} \mathrm{C}$ & $5 \mathrm{~S}$ & $87-105$ \\
& & & & \\
U1-U1-F & $5^{\prime}$ GCAATGGAAGGGCCTCCTCCT & $61^{\circ} \mathrm{C}$ & U1 & $49-69$ \\
U1-U1-R & $5^{\prime}$ TTCGGTTGGGCTGATGCCTG & $61^{\circ} \mathrm{C}$ & U1 & $72-91$ \\
\hline
\end{tabular}

Abbreviations: a.p., annealing position within each RNA coding region; a.r., annealing region; $\mathrm{T}$, annealing temperature; U1, U1 small nuclear RNA coding region; 5S, 5S ribosomal RNA coding region.

used to compare the ends of both the forward and reverse sequences obtained from each clone, which were subsequently overlapped by hand. Sequences obtained were subjected to a sequence-similarity search against the DDBJ/EMBL/GenBank nucleotide collection databases using the blastn algorithm. Sequences similar to other 5S, U1 and their intergenic spacers were deposited in the DDBJ/EMBL/GenBank databases under the accession numbers specified in Table 1 . The pair-wise comparisons were also performed in the Blast 2 sequences tool and multiple sequence alignments were carried out in ClustalW 2.0 (Larkin et al., 2007), and manually adjusted for local optimisation in MEGA 4.0.2 (Tamura et al., 2007). The number of polymorphic sites was retrieved from DnaSP 5.10.0 (Librado and Rozas, 2009). Lengths and p-distances were obtained from MEGA 4.0.2 (Tamura et al., 2007). In p-distance calculation, gaps were not considered, and 1000 bootstrap replicates were performed for the estimation of standard errors.

In order to search for putative regulatory conserved elements, sequences upstream and downstream the $5 \mathrm{~S}$ and U1 regions were analysed. Searches were performed considering the first $100 \mathrm{nt}$ upstream and downstream the RNA coding regions. In the case of U1 upstream analyses, two sequences from the gastropod molluscs Aplysia californica and Lottia gigantea (provided by Manja Marz, Philipps-Universität, Marburg, Germany) were selected and included in the analyses. Conserved motifs were identified by MEME (Bailey and Elkan, 1994) and they were manually compared with published regulatory elements.

$5 \mathrm{~S}$ and U1 sequences were folded in RNAstructure 5.02 (Reuter and Mathews, 2010) at $15^{\circ} \mathrm{C}$, and we used the efn2 function (Mathews et al., 1999) to recalculate the $\Delta \mathrm{G}$ values. The consensus secondary structures were obtained from the RNAalifold webserver (Hofacker, 2003).

We used PALM (Chen et al., 2009) to select nucleotide substitution models and to infer maximum likelihood phylogenies. The best-fit model of nucleotide substitution was directly selected using Modeltest 3.7 (Posada and Crandall, 1998), applying the Akaike information criterion. Phylogenies were constructed by PALM using PhyML (Guindon and Gascuel, 2003). Starting trees were obtained by the BioNJ algorithm (Gascuel, 1997) and 
gaps were treated as unknown characters. The number of substitution rate categories employed was eight, and the bootstrap test (Felsestein, 1985) was used to estimate node support (1000 replicates). Maximum parsimony phylogenies were obtained from PAUP*4.0b10 (Swofford, 2002) as detailed in Vierna et al. (2010). Following Marz et al. (2008), we calculated phylogenetic networks in addition to phylogenetic trees, using the neighbournet algorithm (Bryant and Moulton, 2004), implemented as part of the SplitsTree4 package (Huson and Bryant, 2006).

Different gene tandem arrangements were drawn using pDRAW32 (AcaClone sofware, http://www. acaclone.com/) and we edited all phylogenetic trees in FigTree 1.2.2 (Andrew Rambaut, http://tree.bio.ed. ac.uk/software/figtree/).

\section{Results}

\section{Sequence characterisation}

The identification of 5S, U1 and spacer sequences was performed by comparing them against the DDBJ/ EMBL/GenBank nucleotide collection databases, as explained above. For the sake of clearness, all spacer sequences downstream a $5 S$ will be referred to as NTS, and all spacers downstream a U1, as IGS. All complete 5S sequences were $120 \mathrm{nts}$ and NTS ranged between 283 and 986 nts. All complete U1 sequences were 164 nts except the ones obtained from S. patula, that had a nucleotide insertion at position 37. IGS ranged between 222 and 422 nts. The DDBJ/EMBL/GenBank accession numbers of the sequences studied are listed in Table 1.

Average GC contents were $55.1 \%$ for the $5 S$ region, $54.8 \%$ for the U1 region, $38.8 \%$ for the NTS and $41.9 \%$ for the IGS. The number of polymorphic sites in the RNA coding regions was $S=32$ for the $5 S$ region and $S=20$ for the U1 region.

Hereafter, clones containing partial or complete repeats of both multigene families will be referred to as mixed clones.

\section{Alignments}

An initial alignment of the NTS region showed that the NTSs of razor shells were highly divergent, so sequences had to be grouped separately, according to their similarity. After performing several combinations, we divided the NTSs into seven supergroups and 17 groups. Each supergroup was named using a Roman numeral and each group was denoted by a Greek letter following Vierna et al. (2009). Supergroups and groups contained sequences belonging to one or more species. Similarily, IGS sequences were divided into two groups, one containing all Ensis and Ensiculus and the other one containing Pharus and Siliqua IGSs. The species composition, lengths and mean $P$-distances for each spacer group and supergroup were recorded in Table 3.

Let's now consider only the spacer sequences from mixed clones. We were able to align all IGSs from Ensis, Ensiculus, Pharus and Siliqua individuals, but the divergence among them was evident; however, the last part of the alignment (containing the upstream region of the next $5 S$ repeat) revealed a more conserved region. Quite the opposite, the analysis of the NTSs from mixed clones (upstream U1 sequences) revealed that these spacers were less conserved than the IGSs and could not be aligned at once. In this case, we were able to align all Ensis sequences (from supergroup II), except an NTS from the species E. macha (from supergroup V). The NTSs from the species P. legumen and S. patula, belonging to supergroup IV, could also be aligned together. However, E. cultellus NTSs could not be aligned to Ensis, $P$. legumen or $S$. patula sequences.

In the alignment of Ensis U1-U1 clones (Supplementary File S1), all Ensis IGSs displayed a region of similarity with $\delta$ - and $\gamma$-NTSs, from the species $E$. directus (Conrad, 1843). This region was located at the end of the IGS (just upstream the $5 S$ region) and resembled the last portion of $\delta$ - and $\gamma$-NTSs. Downstream this $5 S$ region, in the NTS, we found another region of similarity with $\delta$ - and $\gamma$-NTSs, and downstream of it there was a fragment resembling a 5S (probably an old pseudogenised copy). Even though this pattern was only found in Ensis species, the first portion of the alignment that corresponded to the U1-IGS-5S sequence (positions 1 to 427, Supplementary file S1), could be aligned to E. cultellus clones, and with more difficulties, to P. legumen and S. patula ones (as explained above).

\section{Upstream elements}

A conserved region was identified at $-25 \mathrm{nts}$ from both the 5S rDNA and U1 snDNA transcription start sites (Supplementary file S2) and named -25 region. It was a TATA-like motif in the 5S upstream sequences (Supplementary file S3a), and upstream the U1 region (Supplementary file S3b), it was an A/G-rich motif: AAAAG in Ensis and E. cultellus, GGGGA in gastropods, AAATG in $P$. legumen and GTAAG upstream S. patula putativepseudogenised U1 sequences (see U1 predicted secondary structures). Another motif (AAAGC, Supplementary file S2) was identified just upstream the U1 snDNA transcription start site, identical to the one found in Drosophila melanogaster (Lo and Mount, 1990) and in other organisms (see Discussion), but it only occurred in some of the razor shell sequences. Finally, a less conserved region was found upstream the -25 region in $\mathrm{U} 1$ snDNA upstream sequences (Supplementary file S2), centred at -44 nts.

Although it was not possible to align all Ensis NTSs at once, we were able to align the $100 \mathrm{nt}$ upstream the transcription start site of 5S rDNA of Ensis species. These stretches were the last part of either NTS or IGS sequences. We failed to include the other Pharidae species in this alignment, as sequences were not conserved among genera.

\section{Internal regulatory regions}

$5 S$ internal control regions (ICR I to IV) were compared with those described in D. melanogaster (Sharp and Garcia, 1988). As some ICRs coincided with the primerannealing regions, some sequences were excluded from the comparisons, and sequences amplified with the 5SUniv primers (Table 2) were only included in the ICR IV analysis. Results were as follows: 12/16 matches within ICR I (positions 3-18); 7/8 matches within ICR II (positions 37-44); 11/14 matches within ICR III (positions 48-61); and 14/21 matches within the ICR IV region (positions 78-98). The degree of conservation of these elements within razor shells was of $14 / 16,8 / 8,13 / 14$ 
Table 3 Intergenic spacer groups and supergroups

\begin{tabular}{|c|c|c|c|c|c|}
\hline NTS group & Species & Clade & $\mathrm{N}$ & Length & Mean P-distance \\
\hline Supergroup I & & & 72 & $286-329$ & $0.135 \pm 0.010$ \\
\hline$\alpha$ & Ensis directus & A & 41 & $321-329$ & $0.011 \pm 0.003$ \\
\hline$\beta$ & Ensis macha & A & 18 & $314-318$ & $0.019 \pm 0.004$ \\
\hline$\zeta$ & Ensis magnus, E. siliqua, E. ensis, E. goreensis & $\mathrm{E}$ & 13 & $286-315$ & $0.042 \pm 0.006$ \\
\hline Supergroup II & & & 28 & 407-965 & $0.240 \pm 0.012$ \\
\hline$\gamma$ & Ensis directus & $\mathrm{A}$ & 11 & $444-654$ & $0.023 \pm 0.004$ \\
\hline$\delta$ & Ensis directus & A & 4 & 407 & $0.002 \pm 0.002$ \\
\hline$\eta^{*}$ & Ensis magnus, E. siliqua, E. ensis, E. minor (Chenu) & $\mathrm{E}$ & 9 & $893-965$ & $0.046 \pm 0.004$ \\
\hline$\theta^{*}$ & Ensis directus, E. macha, E. minor (Dall) & $\mathrm{A}$ & 4 & $926-960$ & $0.127 \pm 0.008$ \\
\hline Supergroup III & & & 14 & $405-620$ & $0.141 \pm 0.009$ \\
\hline$\varepsilon 1$ & Ensis macha & A & 6 & 603 & $0.011 \pm 0.003$ \\
\hline$\varepsilon 2$ & Ensis macha & A & 5 & $618-620$ & $0.004 \pm 0.002$ \\
\hline$\xi^{*}$ & Ensiculus cultellus & & 3 & 405 & $0.010 \pm 0.004$ \\
\hline Supergroup IV & & & 8 & $355-550$ & $0.241 \pm 0.013$ \\
\hline$\mu$ & Pharus legumen & & 3 & $548-550$ & $0.005 \pm 0.002$ \\
\hline$o^{*}$ & Siliqua patula & & 2 & 355 & 0 \\
\hline$\lambda^{*}$ & Pharus legumen & & 3 & $419-420$ & 0 \\
\hline \multicolumn{6}{|l|}{ Supergroup $V$} \\
\hline $1^{*}$ & Ensis macha & A & 1 & 776 & \\
\hline Supergroup VI & & & 2 & 209-369 & $0.077 \pm 0.018$ \\
\hline$\pi^{*}$ & Siliqua patula & & 1 & 369 & \\
\hline$\rho^{*}$ & Siliqua patula & & 1 & 209 & \\
\hline Supergroup VII & & & 2 & $283-332$ & $0.366 \pm 0.029$ \\
\hline$\kappa$ & Pharus legumen & & 1 & 332 & \\
\hline$v^{*}$ & Ensiculus cultellus & & 1 & 283 & \\
\hline IGS group & Species & & $\mathrm{n}$ & Length & Mean P-distance \\
\hline Supergroup Ensis-Ensiculus & & & 15 & $222-422$ & $0.203 \pm 0.015$ \\
\hline Ensis spp. & $\begin{array}{l}\text { Ensis directus, E. macha, E. minor (Dall, 1899) } \\
\text { Ensis magnus, E. siliqua E. ensis E. minor (Chenu, 1843) }\end{array}$ & & 13 & $225-231$ & $0.177 \pm 0.014$ \\
\hline Ensiculus cultellus & Ensiculus cultellus & & 2 & $421-422$ & $0.002 \pm 0.002$ \\
\hline Supergroup Pharus-Siliqua & & & 5 & $236-342$ & $0.193 \pm 0.017$ \\
\hline Siliqua patula & Siliqua patula & & 2 & 236 & $0.064 \pm 0.015$ \\
\hline Pharus legumen & Pharus legumen & & 3 & 342 & $0.007 \pm 0.004$ \\
\hline
\end{tabular}

Abbreviations: A, American clade; E, European clade (Ensis phylogenetic clades according to Vierna et al. (unpublished data)); IGS, intergenic spacer (downstream a U1 small nuclear RNA coding region); n, sample size, NTS, nontranscribed spacer (intergenic spacer downstream a 5S ribosomal RNA coding region).

Asterisks $(*)$ indicate nontranscribed spacers linked to U1 small nuclear DNA;

and 15/21 matches, respectively. Similarly, positions 50-61 (Box A), 80-89 (Box C) and 62-79 (intermediate sequence) were compared with those described by Pieler et al. (1987) in Xenopus laevis, obtaining 6/12, 6/10 and $12 / 18$ matches. Within razor shells, the matches obtained were $9 / 12,7 / 10$ and $14 / 18$.

Six U1 internal regions that appear to be conserved accross metazoa (Zhuang and Weiner, 1986; Marz et al., 2008) were analysed in all razor shell sequences. They were compared with the two gastropod sequences (see above), the ones from the insect D. melanogaster (Lo and Mount, 1990), and those from crustaceans Asellus aquaticus and Proasellus coxalis (Barzotti et al., 2003). Considering as a reference the E. magnus $\mathrm{U} 1$ sequence (see U1 predicted secondary structures), they correspond to the following positions: the $5^{\prime}$ end (includes the $5^{\prime}$ splice site, Zhuang and Weiner, 1986 and references therein); 28-33 (within the U1-70 K protein binding site, Query et al., 1989); the stem-loop II positions 53-55, 65-72 and 84-86 (U1-A protein binding region, Scherly et al., 1989); and positions 124-132 (include the Sm protein binding region, named 'domain $\mathrm{A}^{\prime}$ by Branlant et al., 1982). The most conserved region was the $5^{\prime}$ end (11 nt) that was identical in all sequences. Positions 28-33 were identical in all sequences, but $L$. gigantea had an additional $G$ inserted between the first and the second nt. Positions 65-72 were also identical, except in the last nt. Finally, the 124-132 region was also conserved with the exception of the sixth and last nt. The remaining two regions were conserved at positions 54-55 and 84-85 in all molluscs and arthropods.

\section{Termination signals}

One or more TTTT stretches (required for 5S rDNA transcription termination, Bogenhagen and Brown, 1981; Huang and Maraia, 2001; Richard and Manley, 2009) occurred within the first $20 \mathrm{nt}$ of all NTSs, except for 
those belonging to the $\delta$-group, for which the first perfect TTTT was located at positions 96-99. All NTSs except those from the $\alpha$-group had a TTT motif within the first six nts, and 124/125 sequences had a T residue in the first position.

The analysis of the first portion of the IGS revealed that a TAAAA motif occurred in all Ensis species and E. cultellus, contiguous to the $3^{\prime}$ end of the U1. Sequences from S. patula had a TCCAT and those from P. legumen, an ATATA motif. All sequences displayed between two and four AAT stretches within the first 88 sites downstream the U1 region. However, no other evidence of conserved regions that could be involved in the formation of the $3^{\prime}$ end (as the $3^{\prime}$ box, Hernandez, 1985) were found. The first 50 sites downstream the U1 region were very rich $(44.5 \%)$ in adenines.

\section{Genomic organisation}

Mixed clones of 5S rDNA and U1 snDNA were retrieved from all species analysed, except from E. goreensis (the quality of the extracted DNA was very low) and both multigene families displayed the same orientation. Both U1-5S and 5S-U1 primer pairs yielded PCR products, and amplifications using U1-U1 primers were successful in eight of them (see primer details in Table 2). Tandemly-arranged 5S rDNA repeats (a partial 5S, an NTS and a partial 5S) were retrieved from P. legumen and six Ensis species: E. goreensis, E. magnus, E. siliqua (Linné, 1758), E. ensis (Linné, 1758), E. directus and E. macha; two 5S rDNA repeats flanked by U1 snDNA were sampled from the species $S$. patula and E. cultellus (Figures 1a and b) and tandemly-arranged U1 snDNA repeats were not found in any of the species studied, as clones obtained with the U1-U1 primers always had one or two $5 S$ rDNA repeats in between. The sequence analysis of clone ends permitted us to determine which clones could be overlapped, assuming that identical spacer sequences retrieved from different clones from the same individual were, in fact, the same copy. Therefore, a sequence of $2217 \mathrm{nts}$ was obtained from P. legumen clones (Figure 1c). In all Ensis species, the organisation of mixed clones was very similar and consisted of two partial U1 snDNA repeats flanking one complete $5 S$ rDNA repeat and/or vice-versa (for example, Figure 1d).

One of the two 5S-U1 clones from the species E. macha (Supplementary file S4) was different from all other Ensis clones. It consisted of a partial $5 S$ followed by a divergent NTS (from group 1 , supergroup V). This NTS contained a region of similarity with $\varepsilon-2$ NTSs (from the species E. macha), a $50 \mathrm{nts}$ truncated $5 \mathrm{~S}$ copy, $95 \mathrm{nts}$ very similar to the previous $\varepsilon$-2-similar region and a region that matched to a sequence associated to a Taenia solium spliced leader and spliced leader mini-exon (from Brehm et al., 2002) that appeared to be a silent DNA (Klaus Brehm, personal communication). At the end of the clone, we found the type A U1 sequence (see U1 predicted secondary structures) that was somewhat divergent, with respect to the other Ensis U1s (see Phylogenetic trees and networks).

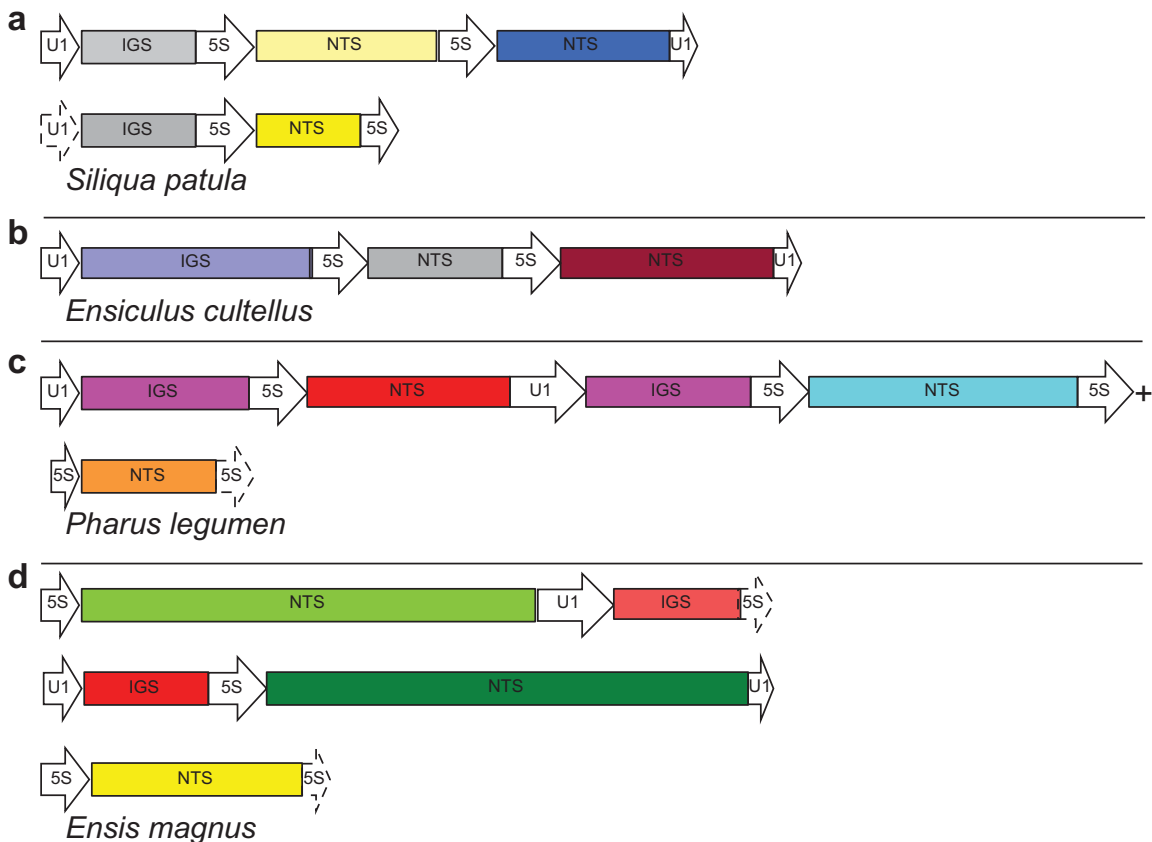

Figure 1 Different 5S ribosomal DNA and U1 small nuclear DNA tandem arrangements sampled from razor shell species. For each species, drawings were constructed using sequences retrieved from the same individual. Drawings are done to scale (except dash lined boxes). (a) Grey IGSs are very similar (identities $=90 \%$, gaps $=2 \%$, E value $=1 \times 10^{-93}$ ); yellow NTSs are similar but the darker one has a deletion of 160 nts (identities $=90 \%$ in both aligned regions, gaps $=4 \%$ in the first region and gaps $=1 \%$ in the second region, $\mathrm{E}$ value $=4 \times 10^{-58}$ ). Blue and yellow NTSs are very divergent and could not be aligned. Blue, $o$-NTS; light yellow, $\pi$-NTS; dark yellow, $\rho$-NTS. (b) NTSs are very divergent and could not be aligned. Grey, v-NTS; brown, $\xi$-NTS. (c) Both IGS (same colour) are identical. The three NTS are very divergent and could not be aligned. Red, $\lambda$-NTS; light blue, $\mu$-NTS; orange, $\kappa-N T S$. (d) Green NTSs (both $\eta$ ) are very similar (identities $=82 \%$, gaps $=9 \%$, E value $=0$ ), red IGSs are also very similar (identities $=92 \%$, no gaps, $E$ value $=1 \times 10^{-93}$ ). Yellow NTS corresponds to $\zeta$-group. $5 S$, 5 S ribosomal RNA coding region; U1, U1 small nuclear RNA coding region; NTS, nontranscribed spacer; IGS, intergenic spacer. $(+)$ Reconstructed by overlapping clones from the same individual (see main text). 


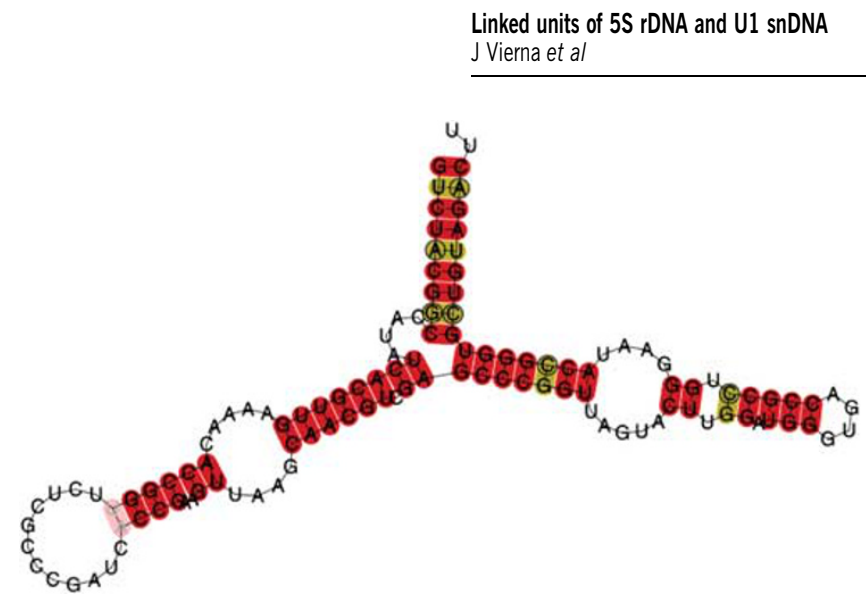

Figure 2 Predicted consensus secondary structure of razor shell 5S ribosomal RNA. Helices are named with Roman numerals and letters correspond to loops, following Barciszewska et al. (2000). Red indicates one type of base pair and ochre indicates two types of base pairs. Pale colours indicate pairs that cannot be formed by all sequences.

\section{$5 S$ predicted secondary structures}

Fourteen different sequences that contained a complete $5 S$ after excluding the primer-annealing regions were considered for the secondary structure prediction. The predicted structures of 11 sequences (Supplementary file S5 a-k) were consistent with the general secondary structure of $5 S$ rRNA (Barciszewska et al., 2000). The presence of two fixed thymines (uracils in the RNA molecule) in positions 80 and 96 caused the formation of an additional mini-loop in helix IV (Figure 2, Supplementary file S5).

The other three sequences (from the species E. ensis, E. siliqua and E. directus) may be pseudogenised sequences, because they displayed abnormal secondary structures (Supplementary file S5 l-n). The $\Delta \mathrm{G}$ values (Table 4) of these putative pseudogenes were the most positive ones, indicating that the structures are less stable.

Compensatory changes $\mathrm{C}-\mathrm{G} \rightarrow \mathrm{A}-\mathrm{T}$ occurred at paired positions 8-111 in the E. cultellus sequence (Supplementary file $\mathrm{S} 5 \mathrm{i}$ ). A $\mathrm{C} \rightarrow \mathrm{T}$ change in position 45 (Supplementary file S5 $\mathrm{j}$ and $\mathrm{k}$ ) made helix III to be one nt smaller in both P. legumen predicted structures.

\section{U1 predicted secondary structures}

After excluding the primer-annealing regions, 30 razor shell U1 sequences ranging between 48 and 164 nts were obtained. Two of them, from the species E. magnus and $P$. legumen, were complete sequences. The species E. ensis and E. siliqua had identical sequences to E. magnus. Complete U1s were build up by overlapping sequences obtained with primer pairs U1-U1 and 5S-U1 (Table 2) from E. minor (Chenu), E. cultellus and S. patula individuals. Three different clones containing partial U1s were retrieved from the E. macha individual (two 5S$\mathrm{U} 1$ and one U1-U1) and two different U1 types, named $\mathrm{A}$ and $\mathrm{B}$, were characterised. E. macha type A U1 was retrieved from a 5S-U1 clone and lacked $23 \mathrm{nt}$ from its $3^{\prime}$ end, which were completed for secondary structure prediction with the corresponding $3^{\prime}$ end of E. magnus U1. E. macha type B U1 was built up by overlapping the sequence obtained with primers U1-U1 with the sequence obtained from the other 5S-U1 clone. The E. directus and E. minor (Dall) sequences were also completed in order to predict their secondary structures. Complete U1s from the gastropod molluscs A. californica and L. gigantea were included, as explained above, in the analyses.

U1 predicted secondary structures were in agreement with previously proposed ones (for example, that of $D$. melanogaster, Lo and Mount, 1990; and consensus structures for several metozoan groups, Marz et al., 2008) (Figure 3; Supplementary file S6). The secondary structure of stem-loop IV was conserved in razor shells and gastropods and consisted of one hairpin loop, one internal loop, two stems and a central nonpaired region containing the $5^{\prime}$ splice site (Zhuang and Weiner, 1986 and references therein) and the $\mathrm{Sm}$ proteins binding region ('domain A', Branlant et al., 1982). The predicted secondary structure of stem-loop I was similar in all U1s, except E. macha type A U1 and L. gigantea sequences (Supplementary file S6 c and i), whose internal loops were $2-3$ nts bigger. E. macha type B U1, E. directus, A. californica and E. minor (Dall) sequences had two internal loops in stem-loop III (Supplementary file S6 d, e, h, and j), whereas the rest of them had three. Stem-loop II had two internal and one hairpin loop in all structures, except in L. gigantea and E. minor (Dall) (Supplementary file S6 i and $\mathrm{j}$ ), which lacked an internal one. However, this sequence and the one from $S$. patula were considered as putative pseudogenised copies because of their abnormal predicted secondary structures and their $\Delta G$ values (Supplementary file S6 j and k; Table 4).

\section{Phylogenetic trees and networks}

Phylogenetic trees were constructed both under maximum likelihood and maximum parsimony criteria and the resulting tree topologies were consistent in all cases. All trees shown were constructed with no outgroups.

The phylogenetic trees and the network performed with the $5 S$ sequences of razor shells did not show a clear clustering by species. However, they also failed to show a well-supported clustering by $5 S$ variants (Supplementary file S7).

We were able to align the upstream region of Ensis 5S rDNA, and the phylogenies performed showed that $5 \mathrm{~S}$ rDNA can be divided into four different groups according to their upstream sequences (see Figure 4).

Because of the impossibility of aligning all NTSs at once due to their high degree of divergence, NTS phylogenies were performed considering each one of 
Table $4 \Delta \mathrm{G}$ values calculated at $15^{\circ} \mathrm{C}$ using the efn2 function for each predicted secondary structure

\begin{tabular}{|c|c|c|c|c|c|}
\hline$\Delta \mathrm{G}\left(\mathrm{kcal} \mathrm{mol}^{-1}\right)$ & Species & NTS group & Linked to U1 snDNA? & Complete sequence? & m.s. (nts) \\
\hline \multicolumn{6}{|l|}{$5 S$ rRNA } \\
\hline-46.5 & Ensis ensis & $\zeta$ & No & Yes & 120 \\
\hline-47.6 & Ensis siliqua & $\eta$ & Yes & Yes & 120 \\
\hline-49.6 & Ensis directus & $\alpha$ & No & Yes & 120 \\
\hline-52.0 & Pharus legumen & $\lambda$ & Yes & Yes & 120 \\
\hline-52.2 & Pharus legumen & $\lambda$ & Yes & Yes & 120 \\
\hline-54.0 & Ensiculus cultellus & $v$ & Yes & Yes & 120 \\
\hline-54.9 & Ensis directus & $\alpha$ & No & Yes & 120 \\
\hline-55.2 & Siliqua patula & $\rho$ & Yes & Yes & 120 \\
\hline-55.2 & Siliqua patula & $\pi$ & Yes & Yes & 120 \\
\hline-55.2 & Siliqua patula & $o$ & Yes & Yes & 120 \\
\hline-55.2 & Ensis directus & $\alpha$ & No & Yes & 120 \\
\hline-55.2 & Ensis directus & $\alpha$ & No & Yes & 120 \\
\hline-56.6 & Ensis directus & $\delta$ & No & Yes & 120 \\
\hline-56.6 & Ensis minor (Chenu) & $\eta$ & Yes & Yes & 120 \\
\hline-56.6 & Ensis macha & $\theta$ & Yes & Yes & 120 \\
\hline-56.6 & Ensis magnus & $\eta$ & Yes & Yes & 120 \\
\hline-56.6 & Ensis directus & $\gamma$ & No & Yes & 120 \\
\hline-56.7 & Ensis ensis & $\eta$ & Yes & Yes & 120 \\
\hline$\Delta \mathrm{G}\left(\mathrm{kcal} \mathrm{mol}^{-1}\right)$ & Species & \multicolumn{2}{|c|}{ Linked to $5 S$ rDNA? } & Complete sequence? & m.s. (nts) \\
\hline \multicolumn{6}{|l|}{ U1 snRNA } \\
\hline-70.1 & Siliqua patula & \multicolumn{2}{|r|}{ Yes } & Yes & 165 \\
\hline-70.3 & Ensis minor (Dall) & \multicolumn{2}{|r|}{ Yes } & No & 164 \\
\hline-83.9 & Aplysia californica & \multicolumn{2}{|r|}{ No } & Yes & 161 \\
\hline-84.7 & Ensis macha A & \multicolumn{2}{|r|}{ Yes } & No & 164 \\
\hline-85.4 & Ensis macha $\mathrm{B}$ & \multicolumn{2}{|r|}{ Yes } & Yes & 164 \\
\hline-85.9 & Ensis minor (Chenu) & \multicolumn{2}{|r|}{ Yes } & Yes & 164 \\
\hline-86.1 & Ensis directus & \multicolumn{2}{|r|}{ Yes } & No & 164 \\
\hline-86.2 & Ensis siliqua & \multicolumn{2}{|r|}{ Yes } & Yes & 164 \\
\hline-86.2 & Ensis magnus & \multicolumn{2}{|r|}{ Yes } & Yes & 164 \\
\hline-86.2 & Ensis ensis & \multicolumn{2}{|r|}{ Yes } & Yes & 164 \\
\hline-87.9 & Ensiculus cultellus & \multicolumn{2}{|r|}{ Yes } & Yes & 164 \\
\hline-87.9 & Pharus legumen & \multicolumn{2}{|r|}{ Yes } & Yes & 164 \\
\hline-91.3 & Lottia gigantea & \multicolumn{2}{|r|}{ No } & Yes & 166 \\
\hline
\end{tabular}

Abbreviations: IGS, intergenic spacer (downstream a U1 small nuclear RNA coding region); m.s., molecule size; NTS, non-transcribed spacer (intergenic spacer downstream a 5S ribosomal RNA coding region); nts, nucleotides; U1 snDNA, U1 small nuclear DNA; U1 snRNA, U1 small nuclear RNA; 5S rDNA, 5S ribosomal DNA; 5S rRNA, 5S ribosomal RNA.

Most positive $\Delta \mathrm{G}$ values correspond to less stable structures. Bold values correspond to putative pseudogenised copies (see main text).

the supergroups with $n \geqslant 3$ (see Table 3). In supergroup I phylogeny (Figure 5a), each NTS group was recovered as monophyletic with high bootstrap support, and $\alpha$ - and $\beta$ sequences were included in a highly supported clade. In supergroup II phylogeny (Figure $5 b$ ), $\theta$ - and $\eta$-sequences (from mixed clones) were included in the same clade (bootstrap value of 100), with respect to a clade formed by $\gamma$ - and $\delta$-sequences. However, $\theta$-sequences were very similar to $\gamma$-and $\delta$-sequences in some regions of the alignment, and may represent an intermediate state between $\eta$ - and $\gamma$-/ $\delta$-NTSs. The alignment of supergroup III sequences displayed an unexpected similarity between E. macha and E. cultellus NTSs (which appeared to be somewhat conserved among different genus). However, in the corresponding phylogeny, each NTS group was highly supported (Figure 5c). Supergroup IV alignment also revealed a certain degree of conservation among NTSs retrieved from different genus, and the phylogeny supported each NTS group with the highest value (Figure 5d).

Sequences considered for the U1 secondary structure prediction were subjected to phylogenetic analyses, excluding putative pseudogenised copies (Figure 6).
Ensis U1 sequences were included in a nonsupported clade, and all of them, except the divergent $E$. macha type A U1 were recovered as monophyletic with a bootstrap support of 70. However, if the divergent sequence was excluded from the analysis (tree not shown), then the clade containing all remaining Ensis U1s decreased its bootstrap value. European Ensis sequences were grouped together with a bootstrap value of 91. Razor shell and gastropod sequences were reciprocally monophyletic with the highest support.

Two different phylogenies of IGS sequences were performed (Figure 7), one including supergroup Ensis-Ensiculus sequences, and another one including supergroup Pharus-Siliqua ones. The phylogeny of supergroup Ensis-Ensiculus (Figure 7a) recovered American and European Ensis sequences, as reciprocally monophyletic with high bootstrap support; the same happened with Ensis and Ensiculus sequences. In this tree, IGSs from the species E. macha were the ones located downstream type B U1s (no IGS downstream the type A U1 was sampled). The phylogeny of supergroup Pharus_Siliqua (Figure $7 \mathrm{~b}$ ) also recovered sequences from each species as monophyletic. 

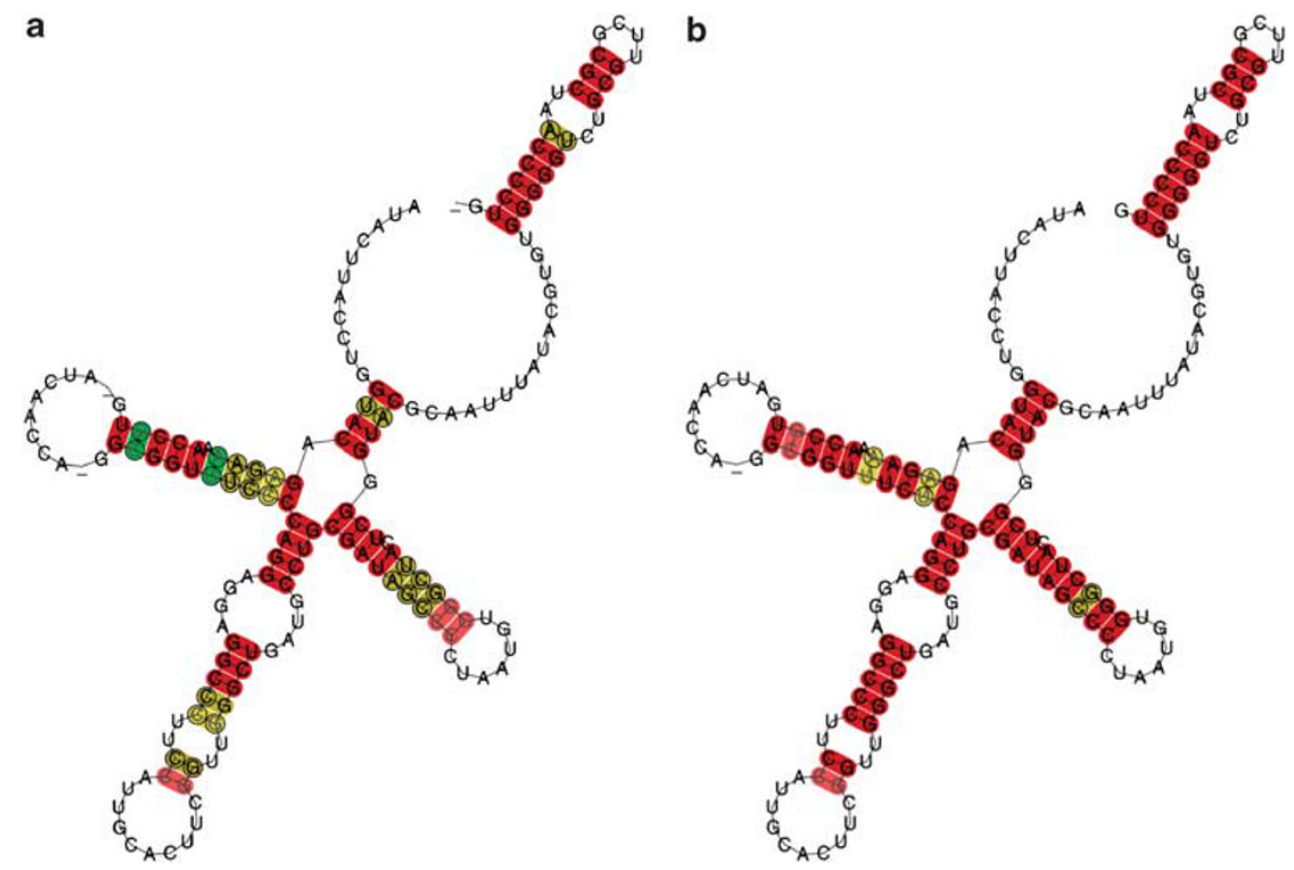

Figure 3 Predicted consensus secondary structure of U1 small nuclear RNA. Stem-loops are indicated by Roman numerals, following Lo and Mount (1990). Red, ochre and green indicates one, two and three types of base pairs, respectively. Pale colours indicate pairs that cannot be formed by all sequences. (a) Including razor shell and gastropod sequences. (b) Including only razor shell sequences.

\section{Discussion}

\section{Long-term evolution of $5 \mathrm{~S}$ rDNA in Pharidae}

The $5 \mathrm{~S}$ region of razor shells was not very polymorphic but the last three sites varied widely when considering the whole dataset. This means that the real number of variants in each species is higher than the number of predicted secondary structures obtained (because we only used complete 5Ss, after excluding the primerannealing regions, for secondary structure prediction). We characterised several $5 S$ sequences and found that a single species could have more than one $5 S$ variant and that some of these variants were shared among species. Similarily, some NTSs were more closely related to NTSs from other species (and genera) than to NTSs from the species they were retrieved from. Therefore, the existence of divergent NTS sequences predates the speciation of the group. Several variants likely already occurred in the most recent common ancestor of the Pharidae (ancestral polymorphism) and some of them were retained until the present time.

The presence of pseudogenes in a multigene family strongly suggests that it evolves under a birth-and-death process (Rooney and Ward, 2005 and references therein). In this survey, we have found putative pseudogenised and truncated $5 \mathrm{~S}$ copies. However, the long-term evolution of $5 \mathrm{~S}$ rDNA in Pharidae appears to be a more complex issue. New variants arise through gene duplication, some of them are retained in the genome and others accumulate mutations and become pseudogenes (birthand-death process). The action of purifying selection seems to be important to mantain the integrity of the RNA-coding regions and the upstream and downstream elements, and unequal crossing-overs and gene conversions should be also taking part and may be responsible for some of the sequence homogeneity (at least among $5 \mathrm{~S}$ rDNA repeats located in the same array). We could suppose that divergent NTSs are located at different arrays where they have evolved independently, but we have shown that some species (S. patula and E. cultellus) have divergent NTS organised in tandem. In the same way, a few clones containing $\alpha$ - and $\delta$-, and $\alpha$ - and $\gamma$ - NTSs were characterised in E. directus (Vierna et al., 2009), and other studies found an intermixed organisation of $5 \mathrm{~S}$ rDNA variants in grey mullets and E. macha (Gornung et al., 2007; Fernández-Tajes and Méndez, 2009). These findings support the idea that $5 S$ rDNA frequently moves on within genomes (see below). If we consider that a 5S rDNA variant is the result of independent (nonconcerted) evolution in a given genomic location, this variant may have later been transposed into another array containing a different variant. Then, the intermixed organisation would be the result of duplications involving both variants, so they could eventually spread throughout the array. From our results, however, it is not clear whether divergent variants located in the same array are being more and more homogenised through the mechanisms typically involved in the concerted evolution of ribosomal multigene families. In conclusion, the long-term evolution of 5S rDNA in Pharidae has been mainly driven by birthand-death processes and purifying selection. Nevertheless, homogenising mechanisms, such as unequal crossing-overs (favoured by the tandem organisation of $5 S$ rDNA repeats) and gene conversions have been probably taking part, in agreement with what was previously reported on Ensis species (Vierna et al., 2009, 2010). Interestingly, recent studies in various animal groups have come to the same conclusion (Fujiwara et al., 2009; Freire et al., 2010; Úbeda-Manzanaro et al., 2010). Other techniques, such as fluorescent in situ hybridisa- 


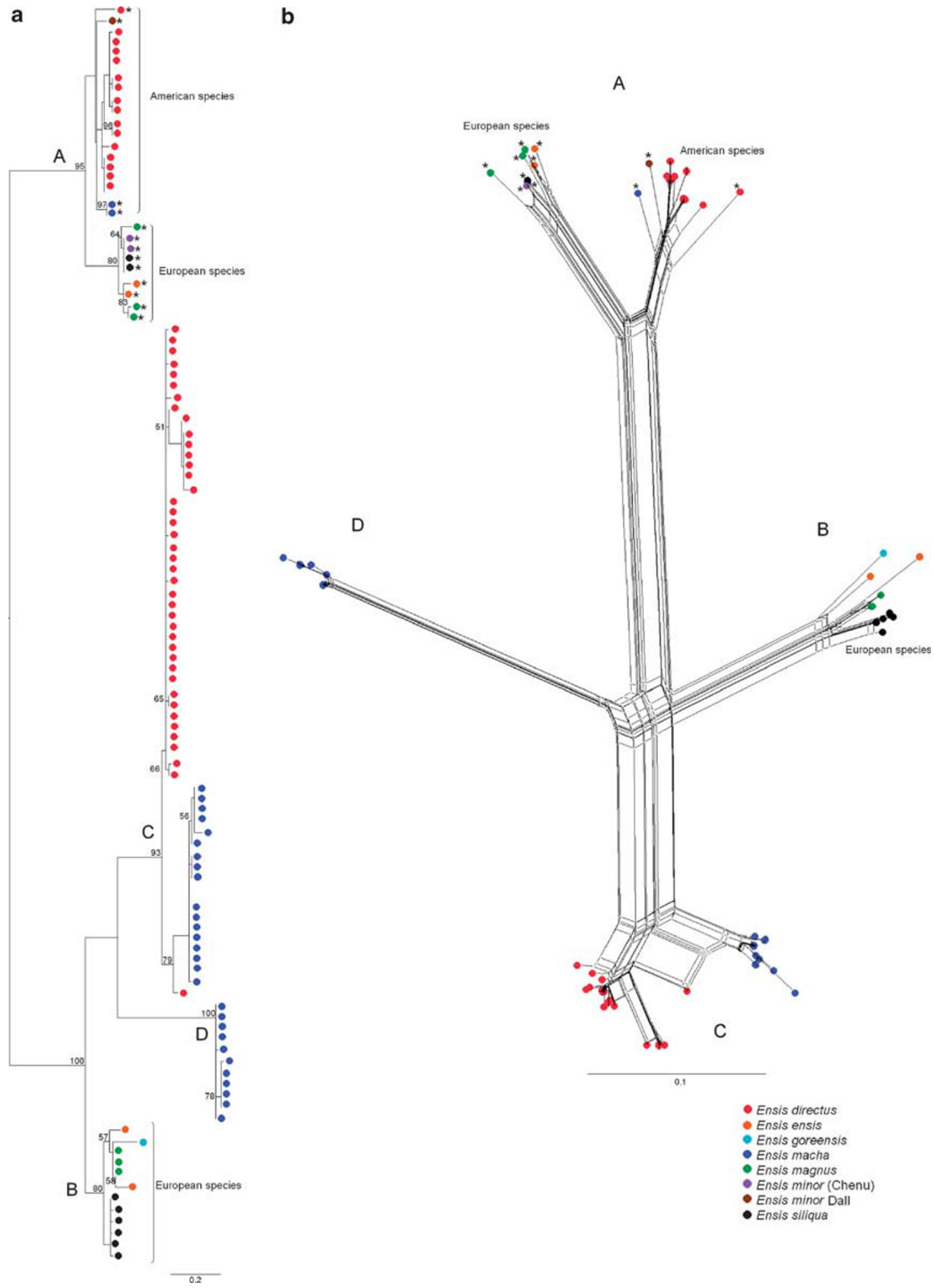

Figure 4 Phylogenetic relationships of the 100 nucleotides upstream the 5S ribosomal DNA transcription start site of Ensis species. Four different types of upstream regions (A-D) are identified. Upstream region (A) includes sequences from mixed clones of 5S ribosomal DNA and U1 small nuclear DNA of the European species, the American species and sequences from $\gamma$ - and $\delta$-NTSs from E. directus; (B) includes sequences from nonmixed clones of the European species; (C) sequences from the American species (E. directus $\alpha$-NTSs and E. macha $\beta$-NTSs); and (D) sequences from E. macha $\varepsilon-\mathrm{I}$ and $\varepsilon$-II NTSs. The relationships among the different sequences are consistent with the phylogenetic history of the genus, as European and American species are reciprocally monophyletic (Vierna et al. unpublished). However, the phylogenetic pattern must be understood in the light of a birth-and-death evolutionary scenario (see main text). Asterisks $\left({ }^{*}\right)$ indicate the repeats retrieved from mixed clones. (a) Maximum likelihood phylogenetic tree constructed using the $\mathrm{K} 80+\mathrm{G}$ model. Numbers on the tree correspond to nonparametric bootstrap supports (1000 replicates) and they are reported only for nodes with values $\geqslant 50$. Each upstream region type is indicated at the most external node common to all its sequences. (b) Phylogenetic network constructed using the neighbour-net algorithm and uncorrected P-distances. For NTS types, see Table 3. 
a

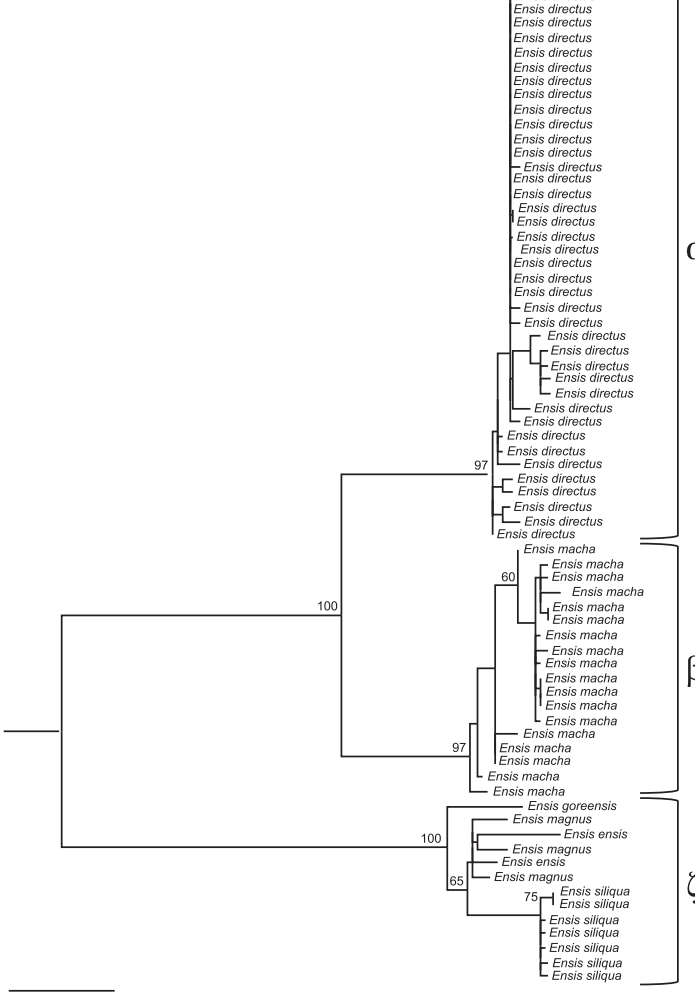

b c

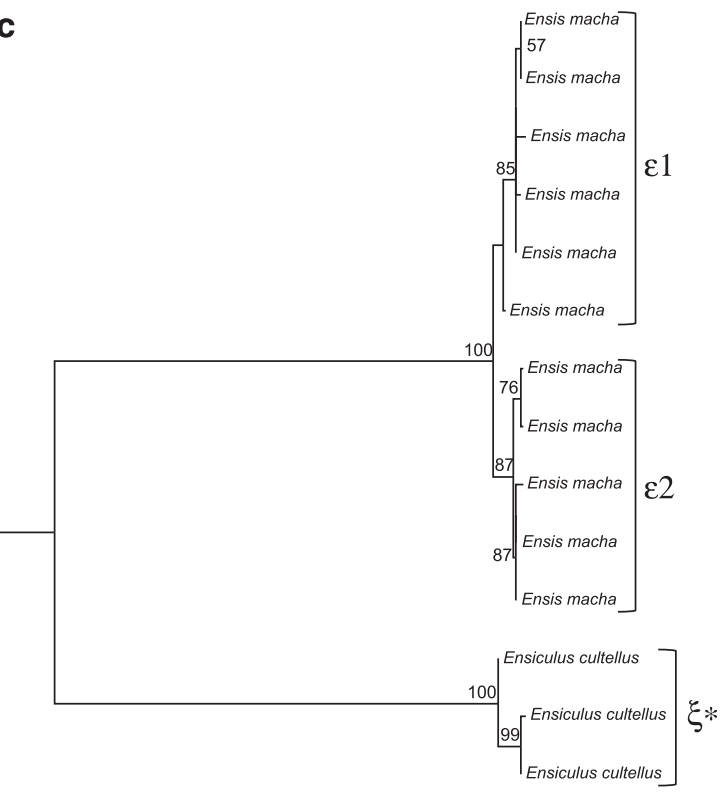

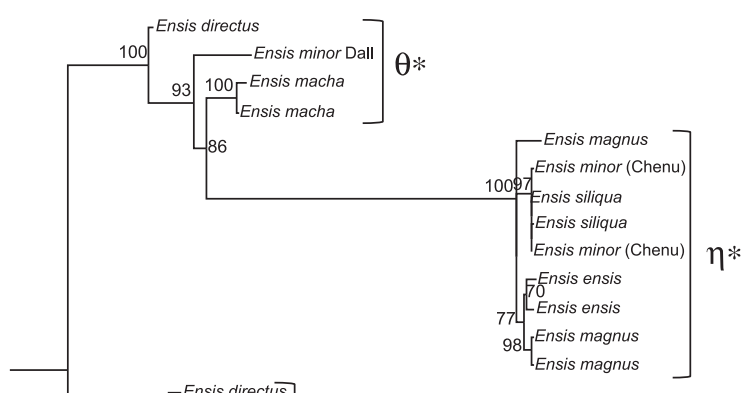

Ensis directus

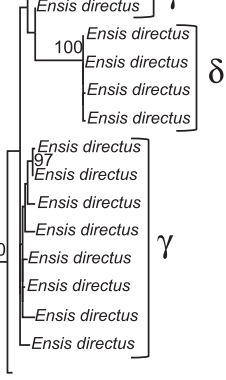

$\overline{0.2}$

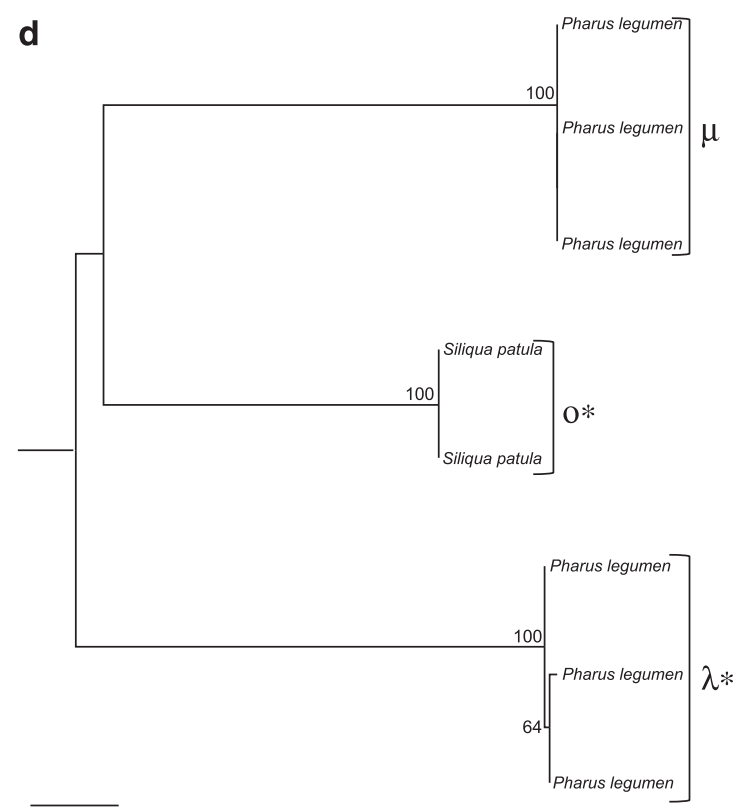

0.06

0.05

Figure 5 Maximum likelihood phylogenies of the nontranscribed spacers (NTSs) downstream the 5S ribosomal RNA coding regions of razor shell species. Numbers on the trees correspond to nonparametric bootstrap supports (1000 replicates) and they are reported only for nodes with values $\geqslant 50$. NTSs groups (Table 3 ) are indicated. Asterisks ${ }^{*}$ ) indicate NTS sequences retrieved from mixed clones of $5 S$ ribosomal DNA and U1 small nuclear DNA. (a) Phylogeny of supergroup I NTSs reconstructed by the TVM + G model. (b) Phylogeny of supergroup II NTSs reconstructed by the TVM + G model. (c) Phylogeny of supergroup III NTSs reconstructed by the K81uf + G model. (d) Phylogeny of supergroup IV NTSs reconstructed by the GTR + G model.

tion may provide interesting data regarding the chromosomal locations of 5S rDNA arrays in razor shells and this should be an issue for further research.

\section{U1 snDNA variation}

We have characterised U1 snDNA for the first time in Bivalvia. Some of the species shared the same U1 variant, 


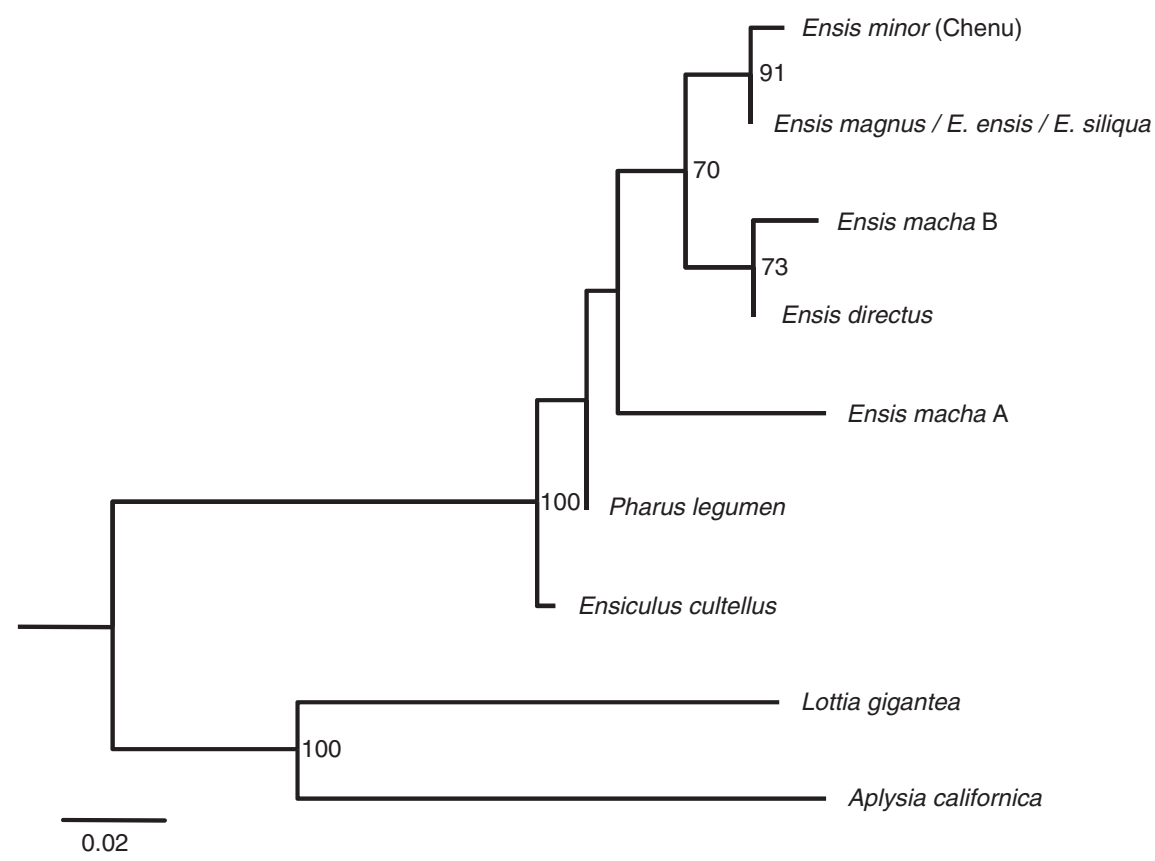

Figure 6 Maximum likelihood phylogeny of the U1 small nuclear RNA coding region of the razor shell and gastropod species, reconstructed using the K81 + I model. Sequences analysed correspond to putative functional copies on the basis of their predicted secondary structures and free energies. Numbers on the tree correspond to nonparametric bootstrap supports (1000 replicates). They are reported only for nodes with values $\geqslant 50$. Ensis macha type A and E. directus sequences were completed with the last $23 \mathrm{nts}$ of the E. magnus sequence (see main text).

many others had a single U1 (not shared) variant and one of them (E. macha) had two different U1s, named type A and type $B$. The phylogeny of the $U 1$ region places the E. macha type A sequence outside the clade formed by the other Ensis sequences. Taking into consideration that the relationships between this clade and the E. cultellus, $P$. legumen and E. macha type A sequences were not resolved, the latter one could be an old copy that diverged before the speciation of Ensis. However, it could well be a pseudogenised copy too (for example, derived from the type B U1) because the -25 region was different in two sites compared with the other Ensis sequences. We cannot be sure whether the predicted secondary structure was functional or not, as it was somewhat different compared with the other Ensis structures but had an intermediate $\Delta G$ value.

In the survey by Marz et al. (2008), discernible paralogs of spliceosomal snDNA multigene families were not uncommon within genera or families, but no dramatically different paralogs were found. We should take into account that we have only searched for tandemly repeated U1 snDNA (not found) or U1 snDNA linked to 5S rDNA. This means that dispersed U1 snDNA and U1 snDNA linked to other multigene families may occur in the genomes of Pharidae species, and these (hypothetical) copies and the ones linked to $5 \mathrm{~S}$ rDNA would be paralogs.

We should be cautious regarding U1 snDNA long-term evolution because the number of repeats we obtained from each species was small. In any way, it is clear that duplication events and purifying selection have been involved.

\section{Upstream elements, internal regulatory regions and} downstream elements

The upstream elements, the internal regulatory regions and the termination signals are essential in 5S rDNA transcription, but epigenetic mechanisms were also found to be involved in transcription regulation (Douet and Tourmente, 2007). A TATA-like motif located at around -30 to $-25 \mathrm{nt}$ is essential for efficient transcription in vitro in Caenorhabditis elegans and C. briggsae (Nelson et al., 1998), Neurospora crassa (Tyler, 1987) and D. melanogaster (Sharp and Garcia, 1988). In razor shells, the TATA-like -25 region that we found upstream the $5 S$ rDNA transcription start site is likely to be analogous to that of the mentioned organisms. Among the $5 S$ internal regulatory regions, the ICR II was the most conserved one in the comparisons with $D$. melanogaster ICRs.

The transcription termination signal of $5 \mathrm{~S}$ rDNA has been studied in various organisms and seems to be quite conserved (a TTTT stretch). We have found this element in almost all razor shell NTSs, in agreement with previous findings in other eukaryotes (Bogenhagen and Brown, 1981; Huang and Maraia, 2001).

According to Marz et al. (2008), the classical snDNAspecific proximal sequence elements (PSE) and TATA boxes that have been described in detail for several vertebrates and were highly conserved (Hernandez, 2001; Domitrovich and Kunkel, 2003) are the exception rather than the rule, as the snDNA promoters are highly diverse across metazoa. In Drosophila, there are two elements essential for the efficient initiation of transcription of snDNA families transcribed by RNA polymerase II: they are the PSEA ( -61 to $-41 \mathrm{nt})$, analogous to the vertebrate PSE and the PSEB (from -32 to $-25 \mathrm{nt}$; consensus sequence C/TATGGAA/GA, Lo and Mount, 1990) (Zamrod et al., 1993). In razor shells and gastropods, we have identified an A/G-rich region $(-25$ region; from -27 to $-23 \mathrm{nts}$ ), which was conserved in location and quite conserved in sequence that could correspond to the PSEB. The region centred at around -40 nts upstream the U1 snDNA transcription start site 

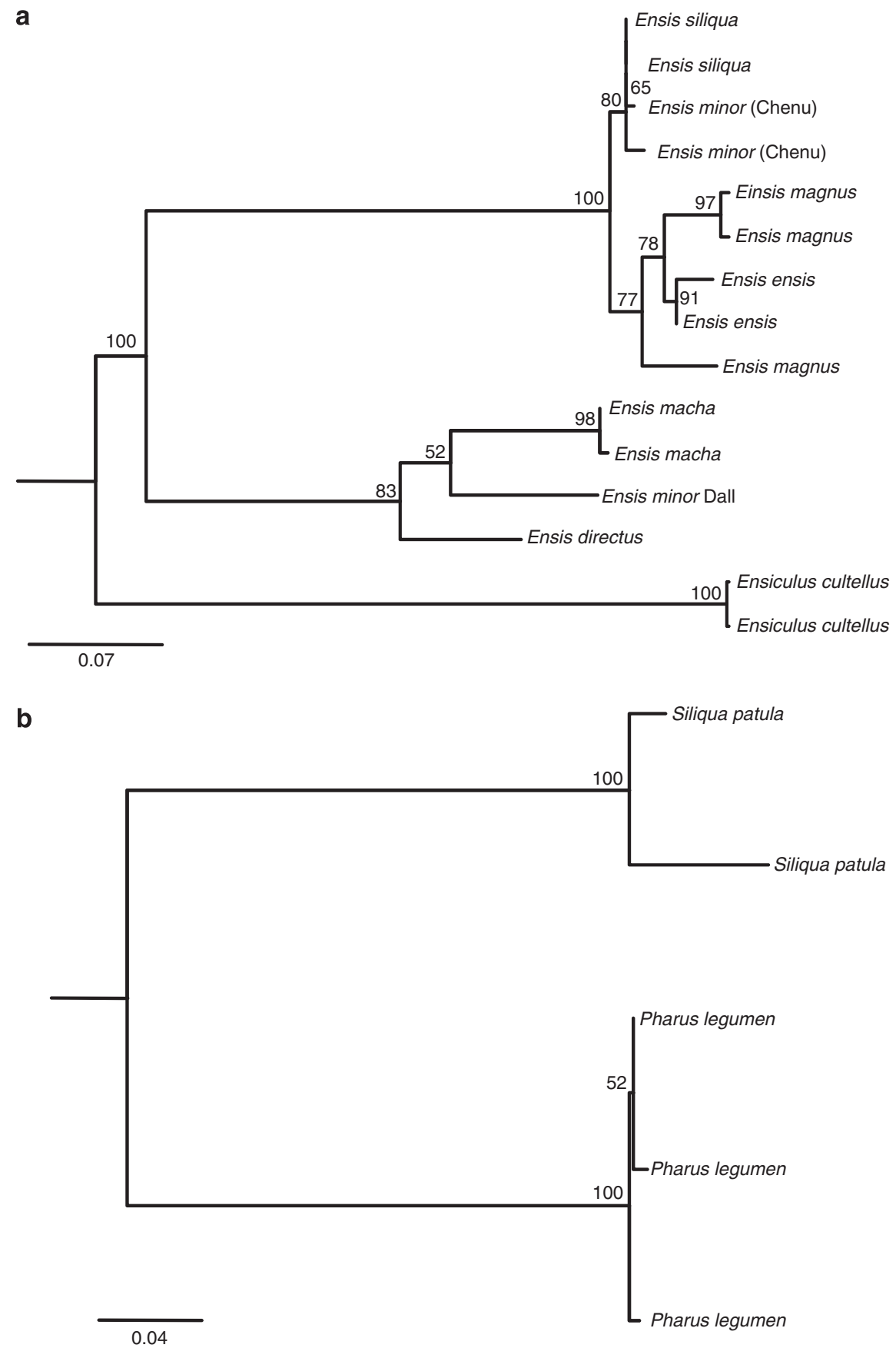

Figure 7 Maximum likelihood phylogenies of the intergenic spacers (IGS) downstream the U1 small nuclear RNA coding region. Numbers on the tree correspond to nonparametric bootstrap supports (1000 replicates). They are reported only for nodes with values $\geqslant 50$ (a) Phylogeny of supergroup Ensis-Ensiculus IGSs reconstructed following the HKY + G model. (b) Phylogeny of supergroup Pharus-Siliqua IGSs reconstructed following the HKY + G model. For IGS types, see Table 3.

was not very conserved, so it does not seem analogous to the PSEA/PSE. Interestingly, an AAAGC motif was found just upstream the U1 snDNA transcription start site of only some of our razor shell sequences (and not in the gastropod sequences). This pentanucleotide is shared with D. melanogaster, the slime mold Physarum polycephalum and some vertebrates (Lo and Mount, 1990 and reference therein). According to our data, it is not conserved in molluscs, but the occurrence of this motif in the same location and shared among distantly related taxa suggests it may have a function.
The internal regulatory regions within the $\mathrm{U} 1$ seemed to be somewhat more conserved than the ones within the $5 S$, as some of them were identical in the bivalve, gastropod, crustacean and insect species considered. Our data is consistent with the results by Marz et al. (2008), except in the positions 86, 131 and 132 (from the reference sequence, see Internal regulatory regions) that were not conserved in molluscs.

The snDNA transcription termination is more variable and different genes appear not to use a common process (Richard and Manley, 2009). For instance, transcription of 
human U1 snDNA terminates close to the $3^{\prime}$ box (Cuello et al., 1999), but transcription of U2 snDNA extends about 800 sites beyond it (Medlin et al., 2003). The human $3^{\prime}$ box (Hernandez, 1985) is a $16 \mathrm{nt}$ stretch, located 10 sites downstream the U1. In razor shells, we have not found a conserved region analogous to the $3^{\prime}$ box; however, the first five nts of the IGS were identical in Ensis species and E. cultellus and similar in P. legumen. Sequences from S. patula were somewhat different, but this could be related to the fact that their preceeding U1s were likely to be pseudogenised copies.

\section{One or more linkage events throughout evolution?}

In order to study whether the linkage happened once or more throughout the evolution of the Pharidae lineages, we have constructed several phylogenies and carefully studied the alignments performed. By mapping the $5 \mathrm{Ss}$ from mixed clones on the phylogenetic trees and on the network performed (Supplementary file S7), we tried to detect whether the linkage between the multigene families emerged once or more throughout the evolution of razor shells, but unfortunately, the phylogenies were not resolved.

The alignment of the IGS region supports that the linkage between both multigene families is homologous in these Pharidae species, with the exception of E. macha type A U1. In this case, as we did not sample its downstream IGS, we do not know how similar it would be compared with the other Ensis IGSs. The origin of this clone is unclear, as it could represent a new linkage between both multigene families, or it could be a descendant of the original linkage in which the NTS was replaced.

The most parsimonious explanation for our data is an evolutionary scenario in which the linkage happened only once, in a common ancestor to all the Pharidae species studied. Subsequently, there were duplications involving either the entire linked unit, or any of the RNA coding regions explaining why we have found the different genomic organisations recorded in Figure 1. Sequences started to accumulate mutations and diverged, but purifying selection and, perhaps, other homogenising mechanisms, maintained the integrity of the functional regions. Finally, different units continued to be duplicated and/or deleted across the different Pharidae lineages.

\section{How $5 S$ rDNA and U1 snDNA can become linked and why?}

There are two possible alternatives for both multigene families to become linked: the linkage was the consequence of the insertion of one or more $5 \mathrm{~S}$ rDNA repeats next to one or more $\mathrm{U} 1$ snDNA repeats, or vice-versa. However, how could this happen? Several surveys have suggested that rDNA (both $5 \mathrm{~S}$ rDNA and the major ribosomal genes) frequently moves on from one location to another in the eukaryote genome (Rooney and Ward, 2005; Datson and Murray, 2006; Veltos et al., 2009; Nguyen et al., 2010), and several mechanisms have been proposed to explain this apparent mobility. Drouin and Moniz de Sá (1995) hypothesised that a 5S rDNA transposition could be produced at the DNA level mediated by extrachromosomal circular DNA or by an RNA intermediate. Interestingly, recent surveys have given support to both hypothesis (Kalendar et al., 2008; Cohen et al., 2010). Similarily, Rooney and Ward, (2005) hypothesised that $5 \mathrm{~S}$ rDNA was capable of multiplying and integrating into other areas of the genome through a process the same as, or similar to, retroposition, in filamentous fungi. In a survey concerning the major ribosomal genes, it has been proposed that ectopic recombination (homologous recombination between repetitive sequences of nonhomologous chromosomes) was the primary motive force in the repatterning of these genes in lepidopteran species (Nguyen et al., 2010). Similar to what has been reported for rDNA, Marz et al., (2008) concluded that metazoan spliceosomal snDNA families behave like mobile genetic elements because they barely appear in syntenic positions, as measured by their flanking regions. Therefore, in theory, there are a few possible ways by which $5 \mathrm{~S}$ rDNA and U1 snDNA could have become linked, but why?

Several examples have been reported in which $5 S$ rDNA and U1 snDNA were found linked to each other or to other multigene families in virtually all eukaryote groups. Interestingly, the linkage between $5 S$ rDNA and other multigene families have been repeatedly established and lost throughout evolution in several lineages, but this lack of conservation and the diversity of the linkages make it unlikely that they provide any selective advantage (for example, transcriptional co-regulation, (Drouin and Moniz de Sá, 1995). In the same way, Marz et al., (2008) concluded that tandem repeats of different spliceosomal snDNA families, or of a spliceosomal snDNA family and 5S rDNA, are not conserved over long evolutionary timescales in metazoans. So, even though the linkages between multigene families may provide a benefit that has not been reported yet, they rather seem to us to be the result of stochastic processes within genomes. The high copy number of $5 S$ rDNA would make it quite likely to establish a linkage with another multigene family.

\section{Conflict of interest}

The authors declare no conflict of interest.

\section{Acknowledgements}

We thank Jane Frydenberg and Camilla Håkansson, who were very kind and helpful during lab work in Aarhus Manja Marz for providing gastropod U1 snDNA sequences, her support during bioinformatic analyses and her comments on the paper; Rudo von Cosel for his help regarding razor shell taxonomy and the identification of many of the specimens studied in this survey; Miguel Vizoso for his comments on the manuscript; and Klaus Brehm for providing information about the Taenia spliced leader sequence. This work would have not been possible without the help of the following colleagues (alphabetical order) who kindly provided razor shell specimens: Dan Ayres, Emile Egea, John Havenhand, Iben Heiner, Inés Naya, Lobo Orensanz, Roberto PortelaMíguez, Anja Schulze, John Taylor, Ray Thompson, and Katrine Worsaae. JV has been supported by a 'María Barbeito' fellowship and a travel grant, both from the Consellería de Economía e Industria, Xunta de Galicia (Spain) and the European Social Fund. 


\section{References}

Bailey TL, Elkan C (1994). Fitting a mixture model by expectation maximization to discover motifs in biopolymers. Proc Second Int Conf Intell Syst Mol Biol pp. 28-36. AAAI Press, Menlo Park, California.

Barciszewska MZ, Szymanski M, Erdmann VA, Barciszewski J (2000). 5S Ribosomal RNA. Biomacromolecules 1: 297-302.

Barzotti R, Pelliccia F, Rocchi A (2003). Identification and characterization of U1 small nuclear RNA genes from two crustacean isopod species. Chromosome Res 11: 365-373.

Bogenhagen DF, Brown DD (1981). Nucleotide sequences in Xenopus 5S DNA required for transcription termination. Cell 24: 261-270.

Branlant C, Krol A, Ebel JP, Lazar E, Haendler B, Jacob M (1982). U2 RNA shares a structural domain with U1, U4, and U5 RNAs. EMBO J 1: 1259-1265.

Brehm K, Hubert K, Sciutto E, Garate T, Frosch M (2002). Characterization of a spliced leader gene and of trans-spliced mRNAs from Taenia solium. Mol Biochem Parasitol 122: 105-110.

Bryant D, Moulton V (2004). Neighbor-net: an agglomerative method for the construction of phylogenetic networks. Mol Biol Evol 21: 255-265.

Cabral-de-Mello DC, Moura RC, Martins C (2010). Chromosomal mapping of repetitive DNAs in the beetle Dichotomius geminatus provides the first evidence for an association of $5 \mathrm{~S}$ rRNA and histone $\mathrm{H} 3$ genes in insects, and repetitive DNA similarity between the B chromosome and A complement. Heredity 104: 393-400.

Caradonna F, Bellavia D, Clemente AM, Sisino G, Barbieri R (2007). Chromosomal localization and molecular characterization of three different $5 S$ ribosomal DNA clusters in the sea urchin Paracentrotus lividus. Genome 50: 867-870.

Chen S-H, Su S-Y, Lo C-Z, Chen K-H, Huang T-J, Kuo B-H et al. (2009). PALM: a paralleled and integrated framework for phylogenetic inference with automatic likelihood model selectors. PLoS ONE 4: e8116.

Cohen S, Agmon N, Sobol O, Segal D (2010). Extrachromosomal circles of satellite repeats and $5 \mathrm{~S}$ ribosomal DNA in human cells. Mobile DNA 1: 11

Cosel von R (1993). The razor shells of the eastern Atlantic, part 1: Solenidae and Pharidae I. Arch Moll 122: 207-321.

Cosel von $R$ (2009). The razor shells of the eastern Atlantic, part 2. Pharidae II: the genus Ensis Schumacher, 1817 (Bivalvia, Solenoidea). Basteria 73: 1-48

Cross I, Rebordinos L (2005). 5S rDNA and U2 snRNA are linked in the genome of Crassostrea angulata and Crassostrea gigas oysters: does the (CT)n.(GA)n microsatellite stabilize this novel linkage of large tandem arrays? Genome 48: 1116-1119.

Cuello P, Boyd DC, Dye MJ, Proudfoot NJ, Murphy S (1999). Transcription of the human U2 snRNA genes continues beyond the 39 box in vivo. EMBO J 18: 2867-2877.

Datson PM, Murray BG (2006). Ribosomal DNA locus evolution in Nemesia: transposition rather than structural rearrangement as the key mechanism? Chrom Res 14: 845-857.

Domitrovich AM, Kunkel GR (2003). Multiple, dispersed human U6 small nuclear RNA genes with varied transcriptional efficiencies. Nucleic Acids Res 31: 2344-2352.

Douet J, Tourmente S (2007). Transcription of the 5S rRNA heterochromatic genes is epigenetically controlled in Arabidopsis thaliana and Xenopus laevis. Heredity 99: 5-13.

Drouin G, Moniz de Sá M (1995). The concerted evolution of 5S ribosomal genes linked to the repeat units of other multigene families. Mol Biol Evol 12: 481-893.

Eickbush TH, Eickbush DG (2007). Finely orchestrated movements: evolution of the ribosomal RNA genes. Genetics 175: 477-485.

Freire R, Arias A, Insua AM, Méndez J, Eirín-López JM (2010). Evolutionary dynamics of the 5S rDNA gene family in the mussel Mytilus: mixed effects of birth-and-death and concerted evolution. J Mol Evol 70: 413-426.
Felsestein J (1985). Confidence limits on phylogenies: an approach using the bootstrap. Evolution 39: 783-791.

Fernandez M, Ruiz ML, Linares C, Fominaya A, de la Vega MP (2005). 5S rDNA genome regions of Lens species. Genome 48: 937-942.

Fernández-Tajes J, Méndez J (2009). Two different size classes of $5 \mathrm{~S}$ rDNA units coexisting in the same tandem array in the razor clam Ensis macha: is this region suitable for phylogeographic studies? Biochem Genet 47: 775-788.

Fujiwara M, Inafuku J, Takeda A, Watanabe A, Fujiwara A, Kohno $S$ et al. (2009). Molecular organization of $5 S$ rDNA in bitterlings (Cyprinidae). Genetica 135: 355-365.

Gascuel O (1997). BIONJ: an improved version of the NJ algorithm based on a simple model of sequence data. $\mathrm{Mol}$ Biol Evol 14: 685-695.

Giegerich R, Meyer F, Schleiermacher C (1996). GeneFishersoftware support for the detection of postulated genes. Proc Int Conf Intell Syst Mol Biol 4: 68-77.

Gornung E, Colangelo P, Annesi F (2007). 5S ribosomal RNA genes in six species of Mediterranean grey mullets: genomic organization and phylogenetic inference. Genome 50: 787-795.

Guindon S, Gascuel O (2003). A simple, fast, and accurate algorithm to estimate large phylogenies by maximum likelihood. Syst Biol 52: 696-704.

Hall TA (1999). BioEdit: a user-friendly biological sequence alignment editor and analysis program for Windows 95/98/ NT. Nucl Acids Symp Ser 41: 95-98.

Hernandez N (1985). Formation of the $3^{\prime}$ end of U1 snRNA is directed by a conserved sequence located downstream of the coding region. EMBO J 4: 1827-1837.

Hernandez N (2001). Small nuclear RNA genes: a model system to study fundamental mechanisms of transcription. J Biol Chem 276: 26733-26736.

Hofacker IL (2003). Vienna RNA secondary structure server. Nucleic Acids Res 31: 3429-3431.

Huang Y, Maraia RJ (2001). Comparison of the RNA polymerase III transcription machinery in Schizosaccharomyces pombe, Saccharomyces cerevisiae and human. Nucleic Acids Res 29: 2675-2690.

Huson DH, Bryant D (2006). Application of phylogenetic networks in evolutionary studies. Mol Biol Evol 23: 254-267.

Kalendar R, Tanskanen J, Chang W, Antonius K, Sela H, Peleg O et al. (2008). Cassandra retrotransposons carry independently transcribed 5S RNA. PNAS 105: 5833-5838.

Larkin MA, Blackshields G, Brown NP, Chenna R, McGettigan PA, McWilliam H et al. (2007). Clustal W and Clustal X version 2.0. Bioinformatics 23: 2947-2948.

Librado P, Rozas J (2009). DnaSP v5: a software for comprehensive analysis of DNA polymorphism data. Bioinformatics 25: 1451-1452.

Little RD, Braaten DC (1989). Genomic organization of human 5 $\mathrm{S}$ rDNA and sequence of one tandem repeat. Genomics 4: 376-383.

Lo PCH, Mount SM (1990). Drosophila melanogaster genes for U1 snRNA variants and their expression during development. Nucleic Acids Res 18: 6971-6979.

Manchado M, Zuasti E, Cross I, Merlo A, Infante C, Rebordinos L (2006). Molecular characterization and chromosomal mapping of the 5S rRNA gene in Solea senegalensis: a new linkage to the U1, U2, and U5 small nuclear RNA genes. Genome 49: 79-86.

Marz M, Kirsten T, Stadler PF (2008). Evolution of spliceosomal snRNA genes in metazoan animals. I Mol Evol 67: 594-607.

Mathews DH, Sabina J, Michael Zuker M (1999). Expanded sequence dependence of thermodynamic parameters improves prediction of RNA secondary structure. J Mol Biol 288: 911-940.

Medlin JE, Uguen P, Taylor A, Bentley DL, Murphy S (2003). The C-terminal domain of pol II and a DRB-sensitive kinase are required for $3^{\prime}$ processing of U2 snRNA. EMBO J 22: 925-934.

Morzycka-Wroblewska E, Selker EU, Stevens JN, Metzenberg RL (1985). Concerted evolution of dispersed Neurospora crassa 
5S RNA genes: pattern of sequence conservation between allelic and nonallelic genes. Mol Cell Biol 5: 46-51.

Mount SM, Gotea V, Lin C-F, Hernandez K, Makałowski W (2007). Spliceosomal small nuclear RNA genes in 11 insect genomes. RNA 13: 5-14.

Nei M, Rooney AP (2005). Concerted and birth-and-death evolution of multigene families. Annu Rev Genet 39: 121-152.

Nelson DW, Linning RM, Davison PJ, Honda BM (1998). 5' flanking sequences required for efficient transcription in vitro of 5S RNA genes, in the related nematodes Caenorhabditis elegans and Caenorhabditis briggsae. Gene 218: 9-16.

Nguyen P, Sahara K, Yoshido A, Marec F (2010). Evolutionary dynamics of rDNA clusters on chromosomes of moths and butterflies (Lepidoptera). Genetica 138: 343-354.

Pelliccia F, Barzotti R, Bucciarelli E, Rocchi A (2001). 5S ribosomal and U1 small nuclear RNA genes: a new linkage type in the genome of a crustacean that has three different tandemly repeated units containing $5 \mathrm{~S}$ ribosomal DNA sequences. Genome 44: 331-335.

Peterson RC, Doering JL, Brown DD (1980). Characterization of two Xenopus somatic 5S-DNAs and one minor oocyte-specific 5S-DNA. Cell 20: 131-141.

Pieler T, Hamm J, Roeder RG (1987). The 5S gene internal control region is composed of three distinct sequence elements, organized as two functional domains with variable spacing. Cell 48: 91-100.

Posada D, Crandall KA (1998). Modeltest: testing the model of DNA substitution. Bioinformatics 14: 817-818.

Query CC, Bentley RC, Keene JD (1989). A specific 31nucleotide domain of U1 RNA directly interacts with the $70 \mathrm{~K}$ small nuclear ribonucleoprotein component. Mol Cell Biol 9: 4872-4881.

Reuter JS, Mathews DH (2010). RNAstructure: software for RNA secondary structure prediction and analysis. BMC Bioinformatics 11: 129.

Richard P, Manley JL (2009). Transcription termination by nuclear RNA polymerases. Genes Dev 23: 1247-1269.

Rooney AP, Ward TJ (2005). Evolution of a large ribosomal RNA multigene family in filamentous fungi: birth and death of a concerted evolution paradigm. PNAS 102: 5084-5089.

Scherly D, Boelens W, van Venrooij WJ, Dathan NA, Hamm J, Mattaj IW (1989). Identification of the RNA binding segment of human U1 A protein and definition of its binding site on U1 snRNA. EMBO J 8: 4163-4170.
Sharp S, Garcia A, Cooley L, Söll D (1984). Transcriptionally active and inactive gene repeats within the D. melanogaster $5 S$ RNA gene cluster. Nucleic Acids Res 20: 7617-7632.

Sharp SJ, Garcia AD (1988). Transcription of the Drosophila melanogaster 5S RNA gene requires an upstream promoter and four intragenic sequence elements. Mol Cell Biol 8: 1266-1274.

Shippen-Lentz DE, Vezza AC (1988). The three 5S rRNA genes from the human malaria parasite Plasmodium falciparum are linked. Mol Biochem Parasit 27: 263-273.

Swofford DL (2002). PAUP*. Phylogenetic Analysis Using Parsimony (*and other methods). Version. Sinauer Associates, Sunderland, MA, USA.

Tamura K, Dudley J, Nei M, Kumar S (2007). MEGA4: molecular Evolutionary genetics analysis (MEGA) software version 4.0. Mol Biol Evol 24: 1596-1599.

Tyler BM (1987). Transcription of Neurospora crassa 5 S rRNA genes requires a TATA box and three internal elements. J Mol Biol 196: 801-811.

Úbeda-Manzanaro M, Merlo MA, Palazón JL, Sarasquete C, Rebordinos L (2010). Sequence characterization and phylogenetic analysis of the 5S ribosomal DNA in species of the family Batrachoididae. Genome 53: 723-730.

Veltos P, Keller I, Nichols RA (2009). Geographically localised bursts of ribosomal DNA mobility in the grasshopper Podisma pedestris. Heredity 103: 54-61.

Vierna J, González-Tizón AM, Martínez-Lage A (2009). Longterm evolution of $5 S$ ribosomal DNA seems to be driven by birth-and-death processes and selection in Ensis razor shells (Mollusca: Bivalvia). Biochem Genet 47: 635-644.

Vierna J, Martínez-Lage A, González-Tizón AM (2010). Analysis of ITS1 and ITS2 sequences in Ensis razor shells: suitability as molecular markers at the population and species levels, and evolution of these ribosomal DNA spacers. Genome 53: 23-34.

Will CL, Lührmann R (2005). Splicing of a rare class of introns by the U12-dependent spliceosome. Biol Chem 386: 713-724.

Zamrod Z, Tyree CM, Song Y, Stumph WE (1993). In vitro transcription of a Drosophila U1 small nuclear RNA gene requires TATA box-binding protein and two proximal cisacting elements with stringent spacing requirements. Mol Cell Biol 13: 5918-5927.

Zhuang Y, Weiner AM (1986). A compensatory base change in U1 snRNA suppresses a $5^{\prime}$ splice site mutation. Cell 46: 827-835.

Supplementary Information accompanies the paper on Heredity website (http://www.nature.com/hdy) 